\title{
The Effect of Tube Length, Cold Exit Diameter and Working Gas on The Cold Flow Temperature of Vortex Tube
}

\author{
Muhammad Fadhli Suhaimi $^{{ }^{*}}$, Mohd Hazwan Yusof ${ }^{1}$, Mohamad Nor Hafiz Rashid, and \\ Mohamad Firdaus Basrawi ${ }^{I}$ \\ ${ }^{1}$ Faculty of Mechanical Engineering, Universiti Malaysia Pahang, 26600, Pekan, Pahang.
}

\begin{abstract}
A vortex tube is a simple device which works as a refrigerator, also known as Ranque Vortex Tube, Hilsch Vortex Tube, and Ranque-Hilsch vortex tube. It is used to obtain desired hot and cold gas and is widely used for spot cooling in industry. In vortex tube, the effect of geometrical parameters on the cold flow temperature of vortex tube is still unclear, and effect of certain working gas is unidentified. Hence, the objective of this analysis is to determine the effect of length of the vortex tube, cold exit diameter and different working gas. 3 different tube lengths, 3 different cold exit diameters, and 8 different types of gas are used. Simflow, which is free software, is selected to analyse the effect numerically. From the results, it is clear that the optimum tube length, cold exit diameter, and working gas are $\mathrm{L}=175 \mathrm{~mm}, \mathrm{~d}=4 \mathrm{~mm}$ and helium, respectively.
\end{abstract}

\section{Introduction}

The vortex tube is a simple device working as a refrigerating machine without any moving part, electrical and chemical reaction. It consists of a vortex chamber, a hollow tube, a tangential nozzle, and a control valve. A high-pressure gas stream enters tangentially through the tangential nozzle and splits into two low pressure hot and cold temperature streams. Cold gas stream leaves the tube through a central orifice near the entrance nozzle, meanwhile hot gas stream flows toward regulating valve and leaves the tube. Figure 1 shows the schematic diagram of a vortex tube.

\footnotetext{
*Corresponding author : fadhli.suhaimi@yahoo.com
} 


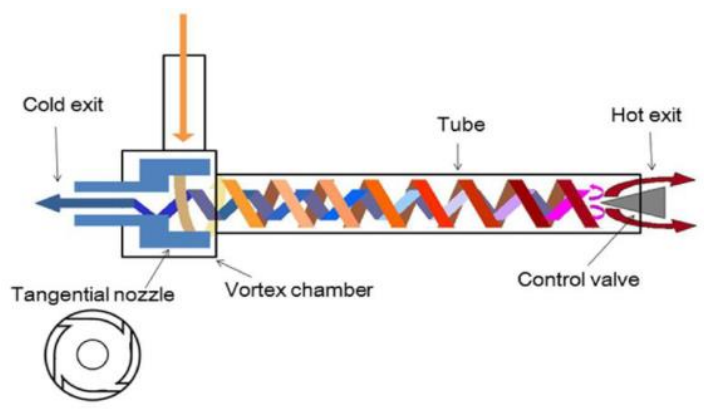

Fig. 1. Schematic diagram of vortex tube [1]

Ranque was the first one who reported this phenomenon of energy separation in a vortex tube [2]. Unfortunately, the physical phenomena or physical mechanism that explain the energy separation inside the vortex tube is not well understood and is not resolved until now [3]. So far there are very plenty of available researches to validate the reliability of CFD analyses for investigating the flow and temperature inside vortex tube. Mohammad O. Hamdan et al. [4] studied the effect of vortex tube length on the performance of vortex tube. The research was conducted under pressure of 4 bar using a vortex tube with three different length; $66 \mathrm{~mm}, 113 \mathrm{~mm}$ and $158 \mathrm{~mm}$. He stated that the medium length which is $113 \mathrm{~mm}$ was the optimum length for the vortex tube. Orhan Aydın and Muzaffer Baki [5] experimentally investigated four different lengths of the vortex tube, $\mathrm{L}=750,550,350$ and $250 \mathrm{~mm}$. Their result showed that length with $350 \mathrm{~mm}$ presented the optimum results for the highest possible temperatures. N.F. Aljuwayhel et al. [6] conducted a numerical study using $100 \mathrm{~mm}$ to 400 $\mathrm{mm}$ of tube length, with $100 \mathrm{~mm}$ of increment. They reported that tube length of $300 \mathrm{~mm}$ was the optimum tube length. If the length is further increases to $400 \mathrm{~mm}$, the energy separation effect does not change. This is because there is a critical length of the vortex tube over which the majority of the energy transfer takes place. Therefore, they concluded that by increasing the length, the performance might not increase, i.e. a better performance will not be achieved. N. Agrawal et al. [7] used a $10 \mathrm{~mm}$ inner diameter of vortex tube with three different cold orifice diameter which is $3 \mathrm{~mm}, 4 \mathrm{~mm}$, and $5 \mathrm{~mm}$. The ratio between cold orifice and inner tube diameter is $\mathrm{d} / \mathrm{D}=0.3,0.4,0.5$. He concluded that $\mathrm{d} / \mathrm{D}=0.4$ give the highest cold temperature different which is $\Delta T \mathrm{c}=6 \mathrm{~K}$. In contrast, Seyed Ehsan Rafiee and M.M. Sadeghiazad [8] performed a similar research with $\mathrm{d} / \mathrm{D}=0.5$. They reported that the cold different temperature is higher than N. Agrawal et al., which is $15 \mathrm{~K}$. Sachin U. Nimbalkar and Michael R. Muller [9] studied the effect of cold orifice diameter on the performance of vortex tube. They used $3.454 \mathrm{~mm}, 6.985 \mathrm{~mm}, 9.576 \mathrm{~mm}$ and $12.636 \mathrm{~mm}$ cold orifice diameter. It measured between cold orifice and energy separation. Higher energy separation, better the performance of vortex tube. It shown that $12.636 \mathrm{~mm}$ has the highest energy separation with cold fraction more than 60 percent. Volkan Kirmac1 [10] carried out experiment by using oxygen and air as working gas. He compared these working gas and obtained that oxygen is colder than air. But, when using nozzle with different material, it shown that oxygen has smaller temperature different compared to air. Same goes to another experimental investigated which is using same working gas and conclude that air is much better used for working gas compared to oxygen [11].

In this study, 3 different tube lengths, 3 different cold exit diameters, and 8 different types of working gas were used to determine its effect on the performance of vortex tube. The pressure and temperature distribution inside the vortex tube will also be presented. The analysis is performed using a free licence simulation software named Simflow. 


\section{Physical modelling}

The models of vortex tube were created using Solidwork. It is an excellent software to construct the vortex tube model. The created model is shown in Fig. 2. The parameters of those models are shown in Table 1. 3 different lengths and 3 different cold exit diameters were created, which are $175 \mathrm{~mm}, 186 \mathrm{~mm}, 194 \mathrm{~mm}$, and $4 \mathrm{~mm}, 4.6 \mathrm{~mm}, 5 \mathrm{~mm}$, respectively.

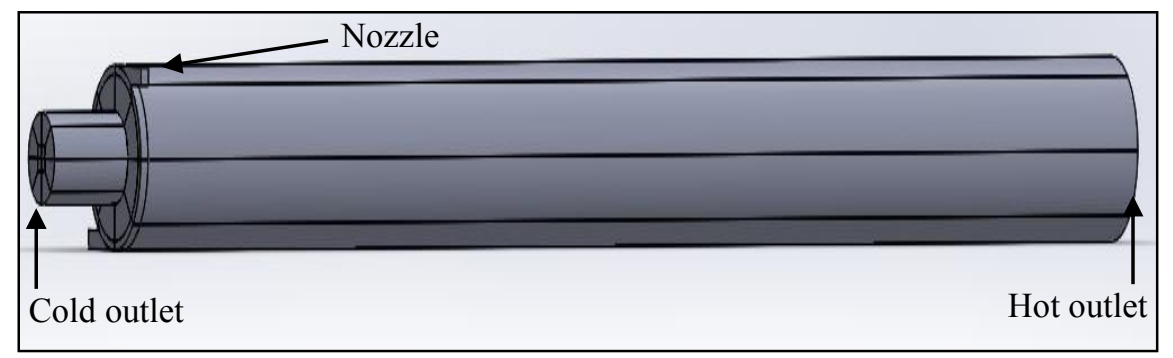

Fig. 2. Vortex tube model using SolidWork.

Table 1. Dimension of vortex tube.

\begin{tabular}{|r|c|c|}
\hline No & Parameter & Dimension and Number \\
\hline 1. & Tube diameter & $10 \mathrm{~mm}$ \\
\hline 2. & Inlet nozzle & $1 \mathrm{~mm} \times 1 \mathrm{~mm}$ \\
\hline 3. & Cold orifice diameter & $4 \mathrm{~mm}, 4.6 \mathrm{~mm}, 5 \mathrm{~mm}$ \\
\hline 4. & Length of tube & $175 \mathrm{~mm}, 186 \mathrm{~mm}, 194 \mathrm{~mm}$ \\
\hline 5. & No. of entry nozzle & 2 \\
\hline
\end{tabular}

Salome was used for meshing the created models. During this process, 4 groups were created to represents the main area of the models, which are 'inlet', 'cold outlet', 'hot outlet', and 'wall'. Each group has its own properties. For example, each parameters have its own node numbers. Higher node numbers, more accuracy the calculation of simulation. Unfortunately, since Salome is a free software, it available for node that below than 100000 nodes. Hence, for a better result, each parameter was created with node numbers within range 90000 nodes. The created mesh was saved as .UNV file, and it was imported by Simflow software to run the simulation. Simflow is a free licence software which is based on OpenFOAM, a simulation software on Linux platform. SimplecFOAM solver were chosen to run the simulation. It is a reconstructed solver based on SimpleFOAM, which use SIMPLE algorithm.

Table 2 shows the boundary conditions setup in Simflow. Table 3 shows the initial setup of the boundary conditions for each group main area of models. In this study, 8 different working gasses are chosen, which are Nitrogen, Ammonia, Hydrogen, Helium, Air, Carbon Dioxide, Carbon Monoxide, and Methane. To the best of authors knowledge, the effect of Carbon Monoxide and Methane as a working gas is still not reported. 
Table 2. Boundary condition setup in Simflow.

\begin{tabular}{|c|c|c|c|c|}
\hline \multicolumn{2}{|c|}{ Patch } & \multicolumn{3}{c|}{ Parameter } \\
\cline { 3 - 5 } Inlet & Type & Fressure (kPa) & Velocity & Temperature (K) \\
\cline { 2 - 5 } & Value & 400 & $\begin{array}{c}\text { Pressure normal } \\
\text { inlet-outlet velocity }\end{array}$ & Fixed value \\
\hline \multirow{3}{*}{$\begin{array}{c}\text { Cold } \\
\text { Outlet }\end{array}$} & Type & Total pressure & - & 300 \\
\cline { 2 - 5 } & Value & 100 & Inlet-outlet & Inlet-outlet \\
\hline \multirow{2}{*}{$\begin{array}{c}\text { Hot } \\
\text { Outlet }\end{array}$} & Type & Total pressure & Inlet-outlet & Inlet-outlet \\
\cline { 2 - 5 } & Value & 300 & - & 300 \\
\hline \multirow{3}{*}{ Wall } & Type & Zero gradient & Fixed value & Zero gradient \\
\cline { 2 - 5 } & Value & - & - & - \\
\hline
\end{tabular}

Table 3. Initial boundary conditions.

\begin{tabular}{|c|c|}
\hline Parameter & Value \\
\hline Pressure & $100 \mathrm{kPa}$ \\
\hline Velocity & 0 \\
\hline Temperature & $300 \mathrm{~K}$ \\
\hline Thermal conductivity & 10 \\
\hline Epsilon & 1000 \\
\hline
\end{tabular}

\section{Result and discussion}

In the present study, the performance of vortex tube is determined by the temperature difference between cold flow and inlet gas, and is defined as follow:

$$
\Delta T_{c}=T_{c}-T_{i}[\mathrm{~K}]
$$

Here, $T_{c}$ is the average temperature of cold flow at cold exit, and $T_{i}$ is the inlet temperature. $T_{c}$ is lower than $T_{i}$. Therefore, the lower value of $\Delta T_{c}$ represents the higher performance of vortex tube.

\subsection{Temperature and pressure distribution inside vortex tube}

Fig. 3 shows the temperature distribution inside the vortex tube for $\mathrm{L}=175 \mathrm{~mm}$ and Helium gas as the working gas. From the simulation result, it is clear that the temperature at the peripheral is higher than the tube centre. The pressure distribution inside vortex tube is shown in Fig. 4. From the figure, it can be understood that the pressure is higher at the peripheral, and lower at the centre of the tube. Lower pressure at the centre is due to the expansion of compressed gas which results a lower temperature than the inlet. 


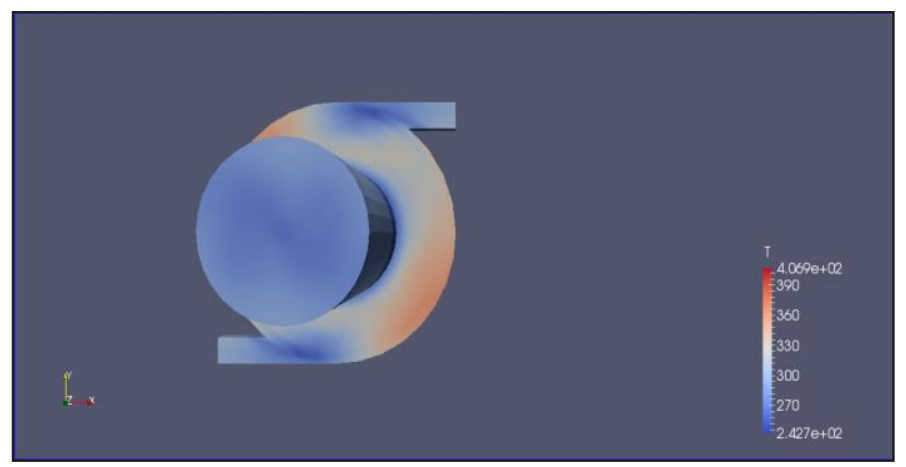

Fig. 3. Temperature distribution for $\mathrm{L}=175 \mathrm{~mm}, \mathrm{~d}=5 \mathrm{~mm}$ and Helium as working gas.

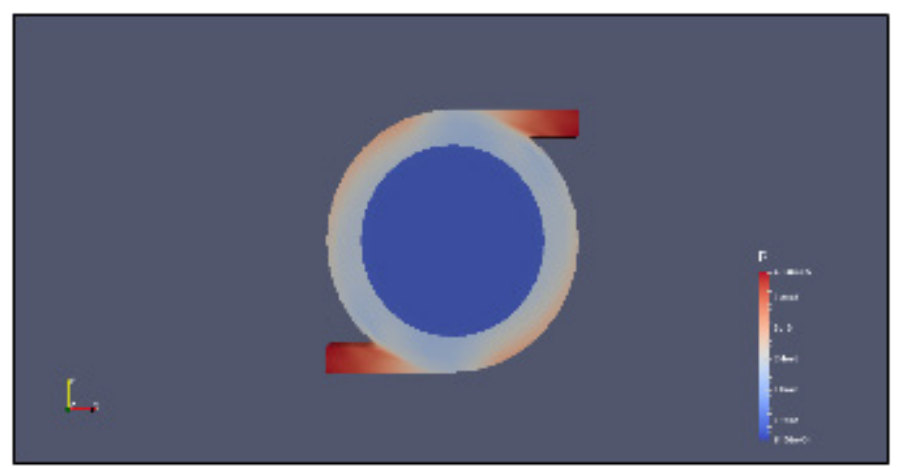

Fig. 4. Pressure distribution for $\mathrm{L}=175 \mathrm{~mm}, \mathrm{~d}=5 \mathrm{~mm}$ and Helium as working gas.

\subsection{Effect of tube length}

3 different lengths $(\mathrm{L}=175 \mathrm{~mm}, \mathrm{~L}=186 \mathrm{~mm}$, and $\mathrm{L}=194 \mathrm{~mm})$ were used to determine the effect of tube length on the performance of the vortex tube. Furthermore, 8 different types of working gas were used to clarify the optimum working gas for vortex tube.

The effect of 3 different tube lengths and 8 types of working gas on the temperature differences, $\Delta T_{c}$ is summarized in Fig. 5. From this figure, it is clear that the optimum length to produce the largest temperature different was obtained at $\mathrm{L}=175 \mathrm{~mm}$ for all types of working gas. Using Helium as the working gas produced the largest temperature different, while Hydrogen produced the smallest temperature different. Nitrogen, air, and carbon monoxide show a similar result. This is due the similarity in specific heat capacity ratio, which is 1.4 . Helium has the highest specific heat capacity ratio, which is 1.67 . Therefore, it can be understood that the higher value of specific heat capacity ratio of a gas produces the lower temperature of the cold flow. The highest performance of vortex tube was obtained when the tube length is $175 \mathrm{~mm}$, and the working gas is Helium. 


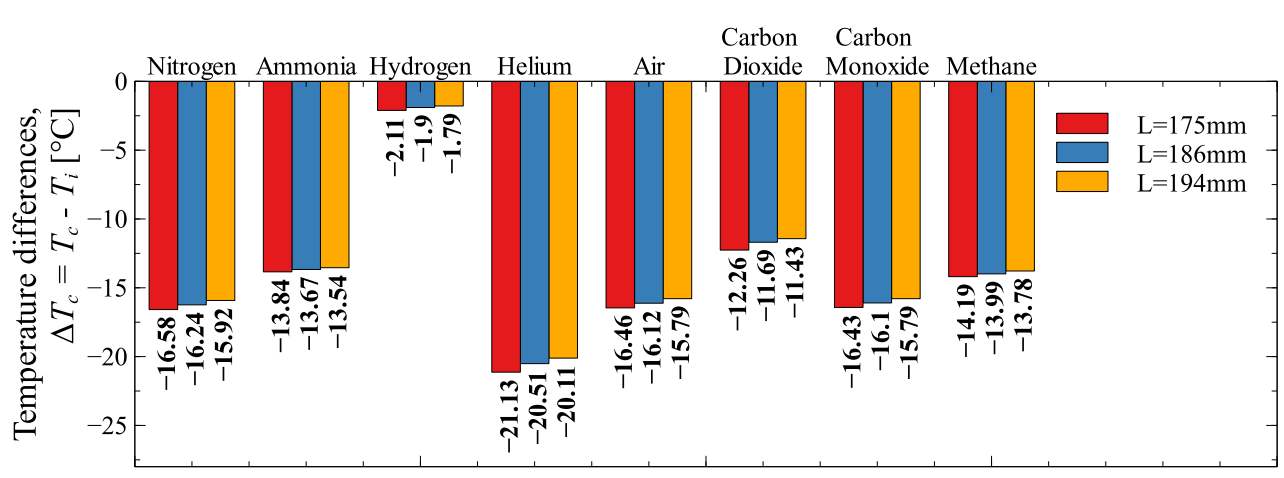

Type of working gas

Fig. 5. The effect of tube length and working gas on the temperature differences, $\Delta T_{c}$.

\subsection{Effect of cold exit diameter}

To determine the effect of cold exit diameter, 3 different diameters were selected, which are $4 \mathrm{~mm}, 4.6 \mathrm{~mm}$, and $5 \mathrm{~mm}$. The result is shown in Fig. 6. Similar to result in subsection 3.2, the largest temperature different was obtained when using Helium as working gas, and the smallest temperature different was obtain when using Hydrogen as working gas. The temperature different increases when the cold exit diameter decreases. Due to the similarity of specific heat capacity ratio, the result of Nitrogen, Air, and Carbon Monoxide was identical to each other. The highest performance of vortex tube was obtained when the cold exit diameter is $4 \mathrm{~mm}$, and the working gas is Helium. Since $d=4 \mathrm{~mm}$ is the smallest value of cold exit dimeter, further investigation using smaller cold exit diameter is needed.

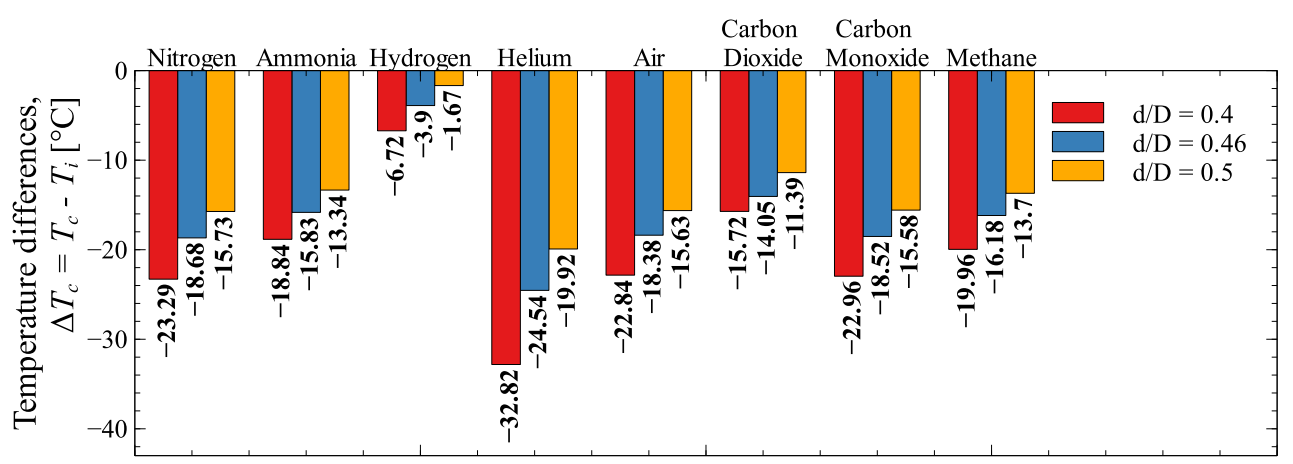

Type of working gas

Fig. 6. The effect of cold exit diameter and working gas on the temperature differences, $\Delta T_{c}$.

\section{Conclusion}

A numerical analysis was conducted to determine the effect of tube length, cold exit diameter, and working gas on the performance of vortex tube. 3 different tube lengths, 3 different cold exit diameters, and 8 different working gas were used. Furthermore, the temperature and pressure distribution inside the vortex tube was also presented. The conclusion are as follows:

1. The pressure is higher at the peripheral of the tube, and lower at the centre of the tube. This is due to the expansion of the compressed gas at the centre, and resulting a lower temperature flow region. 
2. The optimum value of tube length and cold exit diameter are $175 \mathrm{~mm}$ and $4 \mathrm{~mm}$, respectively.

3. Helium is the best option of the working gas due to its high specific heat capacity ratio.

This research was supported by the Ministry of Higher Education and Universiti Malaysia Pahang under grant scheme RDU170137.

\section{References}

1. M. H. bin Yusof, H. Katanoda, MATEC Web Conf. 38, 01006 (2016).

2. G.J. Ranque, Phys. Le Radium 7, 112 (1933).

3. Y. Xue, M. Arjomandi, R. Kelso, Exp. Therm. Fluid Sci. 34, 1367 (2010).

4. M. O. Hamdan, S.-A. B. Al-Omari, A. S. Oweimer, Exp. Therm. Fluid Sci. 91, 306 (2018).

5. O. Aydin, M. Baki, Energy, 31, 2427 (2006).

6. N. F. Aljuwayhel, G. F. Nellis, S. a. A. Klein, Int. J. Refrig. 28, 442 (2005).

7. N. Agrawal, S. S. Naik, Y. P. Gawale, Int. Commun. Heat Mass Transf. 52, 51 (2014).

8. $\quad$ S. E. Rafiee, M. M. Sadeghiazad, Appl. Therm. Eng. 66, 65 (2014).

9. S. U. Nimbalkar, M. R. Muller, Appl. Therm. Eng., 29, (2009).

10. V. Kirmaci, Int. J. Refrig. 32, 1626 (2009).

11. I. Cebeci, V. Kirmaci, U. Topcuoglu, Int. J. Refrig. 72, 140 (2016). 